\title{
The Clinical Profile, Early Warning Score, and Outcome of Children Aged 0-12 Years Referred to a Tertiary Care Hospital in North India
}

\author{
Brinda Eswaramoorthy ${ }^{1}$ Ratan Gupta ${ }^{2}$ Meenakshi Bhatt ${ }^{20}$ Manas Pratim Roy ${ }^{3}$ \\ ${ }^{1}$ Department of Pediatrics, Manipal Hospitals, Bengaluru, Karnataka, \\ India \\ 2 Department of Pediatrics, Vardhman Mahavir Medical College, New \\ Address for correspondence Meenakshi Bhatt, MD, Department of \\ Pediatrics, Vardhman Mahavir Medical College, Ansari Nagar, \\ Delhi, India \\ ${ }^{3}$ Department of Pediatrics, Ministry of Health and Family Welfare, \\ Delhi, India
}

J Child Sci 2021;11:e193-e198.

\begin{abstract}
Keywords

- referral

- Irish PEWS

- pediatric

- mortality

Pediatric patients are referred for multiple reasons, either for better therapeutic services or diagnostic purposes. The clinical condition of patients at the time of referral can significantly affect the outcome of such patients and there is not much data on this aspect. The overall objective of this study was to study the demographic and clinical profile, the causes for referral, and the outcome of pediatric patients being referred to a single tertiary care hospital. This was a prospective observational study done in the Department of Pediatrics of a single tertiary care hospital in North India over the course of 1 year. Patients referred from other health facilities in the age group 0 to 12 years who were admitted in the pediatric ward of the hospital were enrolled. The primary objective was to study the clinical profile and outcome (mortality) of these patients. The secondary objectives were to study the referral pattern of the referred patients, causes for referral, and the severity of illness at the time of admission as assessed by Irish Pediatric Early Warning Score (PEWS) and its correlation with the outcome. The outcomes were categorized as: discharge, death, left against medical advice, referred to other centers, others. Early warning scores are useful to measure the severity of disease and to follow patients' progress. The Irish PEWS score was used in this study to provide a rapid measure of the degree of sickness. Respiratory system disorders and neonatal illnesses were the most common illnesses observed. Most patients had low disease severity as per Irish PEWS score. The overall mortality rate among the referred patients was $19.25 \%$. Patients with younger age, higher scores, neonatal illnesses, and neurological disorders had higher risk of mortality. Training of health personnel at primary and secondary levels in the commonly encountered illnesses will improve provision of care at the local level and decrease low risk referrals.
\end{abstract}

received

January 8, 2021

accepted after revision

May 2, 2021
DOI https://doi.org/

$10.1055 / \mathrm{s}-0041-1731334$.

ISSN 2474-5871. (c) 2021. The Author(s).

This is an open access article published by Thieme under the terms of the Creative Commons Attribution License, permitting unrestricted use, distribution, and reproduction so long as the original work is properly cited. (https://creativecommons.org/licenses/by/4.0/)

Georg Thieme Verlag KG, Rüdigerstraße 14, 70469 Stuttgart, Germany 


\section{Introduction}

Health systems and policies have a critical role in determining the manner in which health services are delivered, utilized, and affect health outcomes. India has a mixed health care system, inclusive of public and private health care service providers. ${ }^{1}$ The public health care system is organized into a three-tier system of primary, secondary, and tertiary levels of care. ${ }^{2}$

Patients are referred for multiple reasons, either for better therapeutic services or diagnostic purposes. The clinical condition of patients at the time of referral can significantly affect the outcome of such patients and there is not much data on this aspect. ${ }^{3,11}$

In a study conducted by Aggarwal et al in Delhi, it was found that most deaths in referred neonates occurred within 24 to 48 hours of admission. ${ }^{3}$

The knowledge of the common diseases that referred patients are found to be suffering from is particularly important in resource allocation and preparedness. Singhi et al conducted a retrospective analysis of patients referred to a tertiary care hospital in Chandigarh and a community level hospital in Haryana from 1999 to $2000 .{ }^{4}$ The most common morbidities were diarrhea and respiratory infections, and neonatal deaths were a major proportion of all the deaths.

There is only a handful of data regarding the referral patterns and outcome of referred patients in pediatric literature. Among these studies, researchers often concentrate on a particular age group or a particular disease, e.g., neonatal age group, dermatological illnesses, ${ }^{5}$ etc. Some of these studies are more than a decade old and data from Indian hospitals is scant.

Early Warning Scores are instruments consisting of several clinical parameters, e.g., heart rate, respiratory rate, consciousness scale, etc. They are useful in triage of the patient at arrival. They also guide decisions about transfer to intensive care unit or high dependency unit when available. Also, they help to follow the patient over time for early signs of deterioration. ${ }^{6}$

In this study, the Irish PEWS (Pediatric Early Warning Score) was used. It consists of parameters like temperature, respiratory rate, oxygen therapy, oxygen saturation, heart rate, capillary refill time, systolic blood pressure, and consciousness level. Hence this study was proposed to analyze the demographic and clinical profile, causes for referral, and outcome of referred patients to a tertiary care hospital in North India pertaining to children in the age group of 0 to 12 years.

\section{Methods}

This was a prospective observational study done in the Department of Pediatrics over the course of 1 year (January 2017 to December 2017). Patients referred from other health facilities in the age group 0 to 12 years who were admitted in the Pediatric ward of the hospital were enrolled.

The primary objective was to study the clinical profile and outcome (mortality) of patients in the age group 0 to 12 years referred from other health facilities to our hospital over a 1year period. The secondary objectives were to study the demographic pattern of the referred patients, causes for referral, and the severity of illness at the time of admission as assessed by Irish PEWS ${ }^{7}$ and its correlation with the outcome. At the time of the study, using the Irish PEWS was not part of the standard practice.

\section{Inclusion Criteria}

1. All children aged 0 to 12 years referred from any health care facility outside the hospital including those children who are declared "brought dead."

2. Those informants of patients willing to give informed consent.

\section{Exclusion Criteria}

1. Children who were being treated in another healthy facility and left against medical advice to attend our hospital.

2. Patients referred with surgical conditions.

Newborns were defined as being up to 28 days of age, and infants were defined as up to 365 days of age. Patients who were referred from other health facilities and admitted in the pediatric wards were enrolled after getting written informed consent from the parents/guardian. The study flow is depicted in a flowchart (-Fig. 1). The children were assessed for their severity of illness at the time of admission based on the IrishPEWS scoring system ${ }^{7}$ using an age-appropriate scoring sheet which included parameters like respiratory rate, respiratory effort, oxygen therapy, oxygen saturation, heart rate, capillary refill time, systolic BP, consciousness level, and temperature. The minimum score was 1 and maximum was 20 . The higher the score, the greater was the clinical severity. The rationale for including patients who were brought dead was that we were attempting to study the entire spectrum of the clinical profile of patients being referred to the hospital.

Enrolled patients were followed up during their period of hospital stay and the outcomes were observed and documented and were categorized as: discharge, death (within the first 6 hours, 6-24 hours, 24-48 hours, after 48 hours), Left Against Medical Advice (LAMA), referred to other centers, others.

Using the previous average mortality percentage in the pediatric wards (10\%), a sample size of 400 was arrived at.

All the continuous variables were represented as mean \pm $\mathrm{SD}$ and the range is mentioned. Categorical variables were analyzed by Chi-square test or Fisher's Exact test. The clinical outcome was correlated with the referral background and the severity score using regression analysis. Binomial and multinomial regression was used and fit of the final model was assessed. SPSS version 21 was used for all statistical purposes.

\section{Results}

This study is being reported in line with the STROBE (STrengthening the Reporting of Observational studies in Epidemiology) guidelines. A total of 400 patients were studied. The most common age group was 1 to 11 months (36\%) followed by $<28$ days $(27.5 \%)$ ( - Table 1 ). Children between 1 and 5 years constituted $21.25 \%$ and $>5$ years 


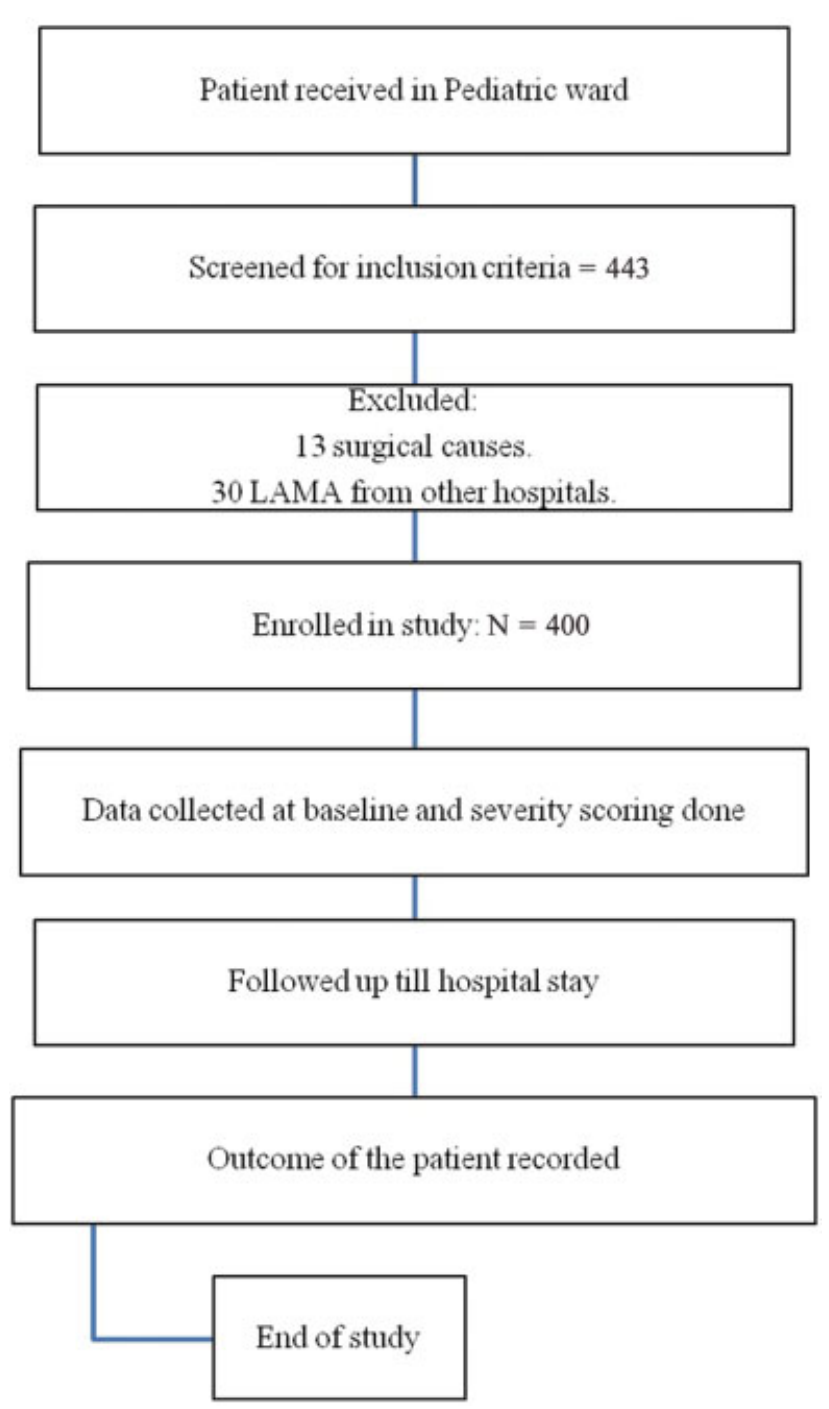

Fig. 1 STROBE study flow. STROBE, STrengthening the Reporting of Observational studies in Epidemiology.

represented $15.25 \%$. Among the referred patients, males outnumbered females (61.75 vs. $38.25 \%$ ).

A majority of (44.75\%) the children belonged to the middle class, $25 \%$ belonged to the lower middle class, $16 \%$ were in the lower class based on modified Prasad scale 2014.

Nearly half of the study population had illness of 1 to 7 days duration (53\%) followed by those with illness $>7$ days (24.5\%). Only around one-fifth of the study children presented to the hospital within 24 hours of onset of illness (22.25\%) (-Table 2). Respiratory illnesses (29.5\%) represented the most common

Table 1 Age of the patients referred

\begin{tabular}{|l|l|l|l|}
\hline S. no & Age group & Frequency & Percentage \\
\hline 1. & $<28 \mathrm{~d}$ & 110 & 27.50 \\
\hline 2. & 1 to $11 \mathrm{mo}$ & 144 & 36 \\
\hline 3. & 1 to $5 \mathrm{y}$ & 85 & 21.25 \\
\hline 4. & $>5 \mathrm{y}$ & 61 & 15.25 \\
\hline & & 400 & 100 \\
\hline
\end{tabular}

Table 2 Duration of illness prior to first hospitalization

\begin{tabular}{|l|l|l|l|}
\hline S. no & Duration of illness & Frequency & Percentage \\
\hline 1. & $<24 \mathrm{~h}$ & 89 & 22.25 \\
\hline 2. & $1-7 \mathrm{~d}$ & 214 & 53.5 \\
\hline 3. & $>7 \mathrm{~d}$ & 97 & 24.25 \\
\hline & & 400 & 100 \\
\hline
\end{tabular}

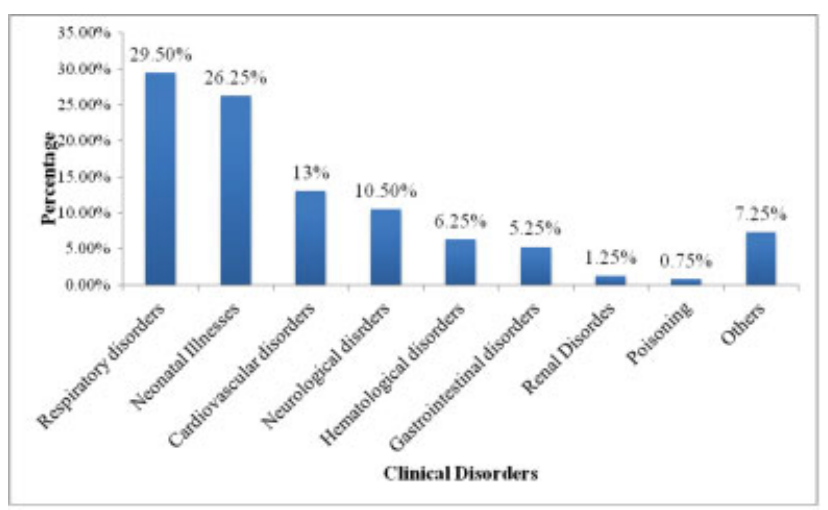

Fig. 2 Clinical disorders for which referred.

cause for referral followed by neonatal illnesses (26.25\%) and cardiovascular disorders (13\%) (-Fig. 2).

The common diseases for which children were referred to the hospital are listed in -Table 3. Among the respiratory disorders, pneumonia was the major cause for referral (74\%), followed by acute bronchiolitis (10\%). Among the neonates who were referred, one-third were premature neonates with common complications like low birth weight, hyaline membrane, etc. (31\%). Birth asphyxia (29\%), sepsis (19\%), and meconium aspiration syndrome $(8 \%)$ were other common causes for referral. This suggests that strengthening of basic neonatal care services and training of personnel at referral centers in the management of these commonly occurring neonatal conditions, could allow these patients to get the requisite care closer to their homes.

The majority of patients were referred from government hospitals both within and outside the state. The patients from private hospitals and clinics represented 9.75\%. The duration of stay in the referring facility was $<24$ hours in a vast majority of the patients (86.5\%). Only a small percent (3\%) of patients had a period of stay $>7$ days.

Most patients were transported by ambulance provided by the referring hospital (79\%), some used a private ambulance $(9.25 \%)$, and the rest reached our hospital by public transport system, their own vehicle or on foot. The vast majority of the patients (92.75\%) were transported without any accompanying health personnel. The bulk (83.5\%) of the study population was not informed about the nature of their illness before referring to our hospital. Most of the patients (88.75\%) had their clinical findings mentioned in their referral slips.

Of the referred pediatric patients, 59.75\% were discharged, $19 \%$ of the patients had died, $15 \%$ had left against 
Table 3 Common illnesses for which referral was done among selected subgroups

\begin{tabular}{|c|c|c|c|}
\hline \multicolumn{4}{|c|}{ Common respiratory illnesses } \\
\hline S. no & Respiratory illness & Frequency & Percentage \\
\hline 1. & Pneumonia & 87 & 74 \\
\hline 2. & Acute bronchiolitis & 12 & 10 \\
\hline 3. & Pleural effusion & 2 & 2 \\
\hline 4. & Empyema thoracis & 3 & 2.5 \\
\hline 5. & TB & 6 & 5 \\
\hline \multirow[t]{2}{*}{6.} & Others & 8 & 6.5 \\
\hline & & 118 & 100 \\
\hline \multicolumn{4}{|c|}{ Common neonatal illnesses } \\
\hline 1. & $\begin{array}{l}\text { Prematurity and its } \\
\text { complications }\end{array}$ & 33 & 31 \\
\hline 2. & Birth asphyxia & 29 & 28 \\
\hline 3. & Sepsis & 20 & 19 \\
\hline 4. & $\begin{array}{l}\text { Meconium } \\
\text { aspiration } \\
\text { syndrome }\end{array}$ & 9 & 8 \\
\hline \multirow[t]{2}{*}{5.} & Others & 14 & 14 \\
\hline & & 105 & 100 \\
\hline \multicolumn{4}{|c|}{ Common cardiovascular illnesses } \\
\hline 1. & $\begin{array}{l}\text { Acyanotic } \\
\text { Congenital Heart } \\
\text { Diseases (ACHD) } \\
\text { and their } \\
\text { complications }\end{array}$ & 32 & 62 \\
\hline 2 & $\begin{array}{l}\text { Cyanotic } \\
\text { Congenital Heart } \\
\text { Diseases (CCHD) } \\
\text { and their } \\
\text { complications }\end{array}$ & 17 & 32 \\
\hline 3. & Pericardial effusion & 1 & 2 \\
\hline \multirow[t]{2}{*}{4.} & $\begin{array}{l}\text { Rheumatic heart } \\
\text { disease }\end{array}$ & 2 & 4 \\
\hline & Total & 52 & 100 \\
\hline
\end{tabular}

medical advice, $3.75 \%$ absconded, and $2.25 \%$ were referred to another health facility. No patients were brought dead during the course of the study.

During the study, more than half the patients had a period of stay of 1 to 7 days (57.75\%). In $26.5 \%$ of patients, the stay exceeded beyond 1 week and $15.75 \%$ had a stay less than a day. Most deaths that occurred in the referred patients were within the first 48 hours of stay (6-24 hours [38.96\%] and 24-48 hours [28.57\%]).

On univariate regression analysis, there was significant $(p<0.05)$ decrease in mortality with increase in age of 1 year by odds of 0.7481 ( - Table 4). In multivariate logistic regression, after adjusting for confounding factors, patients with neonatal illnesses $(p=0.0069)$ and neurological disorders $(p=0.03)$ had a significantly higher mortality as compared with other clinical disorders. There was
Table 4 Univariate regression analysis for correlation of age and gender with outcome (mortality)

\begin{tabular}{|l|l|l|l|l|l|}
\hline & Coefficient & $\begin{array}{l}\text { Std. } \\
\text { error }\end{array}$ & $p$-Value & $\begin{array}{l}\text { Odds } \\
\text { ratio }\end{array}$ & $95 \% \mathrm{Cl}$ \\
\hline Gender & & & 1 & & \\
\hline Female & & & & & \\
\hline Male & -0.037183 & 0.26027 & 0.8864 & 0.9635 & $\begin{array}{l}0.5785- \\
1.6047\end{array}$ \\
\hline Age & -0.29021 & 0.084019 & 0.0006 & 0.7481 & $\begin{array}{l}0.6345- \\
0.8820\end{array}$ \\
\hline
\end{tabular}

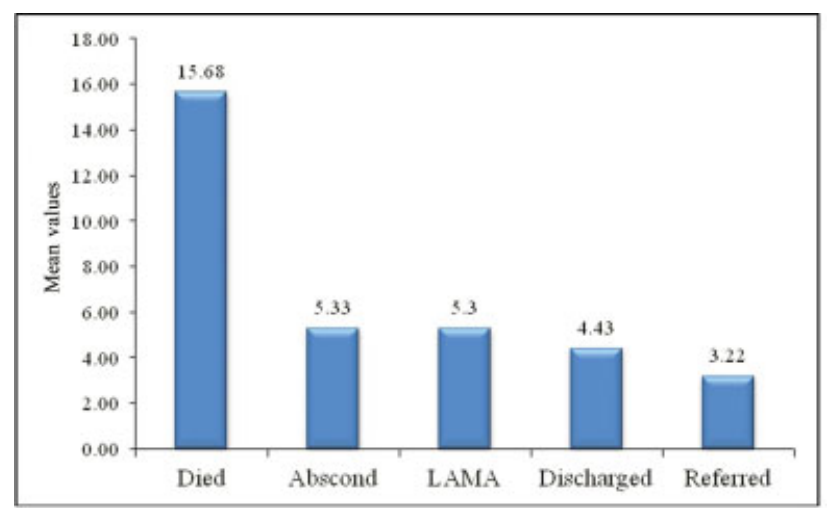

Fig. 3 Average PEWS score in patients with different outcomes. PEWS, Pediatric Early Warning Score.

Table 5 Correlation of PEWS score and mortality by regression analysis

\begin{tabular}{|l|l|l|l|l|l|}
\hline & Coefficient & $\begin{array}{l}\text { Std. } \\
\text { error }\end{array}$ & $p$-Value & $\begin{array}{l}\text { Odds } \\
\text { ratio }\end{array}$ & $95 \% \mathrm{Cl}$ \\
\hline PEWS score & 1.32257 & 0.26796 & $<0.0001$ & 3.7531 & $\begin{array}{l}2.2197- \\
6.3457\end{array}$ \\
\hline
\end{tabular}

a significant association of higher PEWS scores with death $(p<0.001)$ by Chi-square test. There was a significantly higher score $(p<0.001)$ in patients who had died ( - Fig. 3 ) and by regression analysis an increase in PEWS score by 1 unit, the risk of mortality significantly $(p<0.0001)$ increased by odds of 3.7531 (-Table 5).

\section{Discussion}

In our study, it was found that the age group most commonly referred was infants $(63 \%)$ and among these the majority were neonates (43\%). In a study by Shahab et $\mathrm{al}^{8}$ in a tertiary care center in Pakistan, $70 \%$ of patients were found to be less than 5 years of age, with infants contributing $37 \%$ and the male to female ratio was found to be $1.5: 1$. But this data was inclusive of all pediatric admissions and not specific for referred patients.

Most of the patients had to travel an average distance of $25 \mathrm{~km}$ to reach our hospital with a travel time of more than 
an hour. The majority of these patients were not accompanied by health personnel which endangers the patient on the way to the hospital, especially considering the long travel times.

The socioeconomic status of the patients as per the modified Prasad scale (2014) indicated that $44.75 \%$ belonged to the middle class followed by $25 \%$ to the lower middle class. Ours being a large tertiary care government hospital offering much of the treatment without cost, this is the expected socioeconomic profile.

Three-fourths of the study population had an acute illness at the time of referral (duration of up to 7 days). The vast majority $(89.75 \%)$ of patients were referred from government hospitals in Delhi and neighboring states since much of the population cannot afford treatment in private hospitals. The duration for which most patients stayed at the referring facilities was less than 24 hours (86.5\%). Most of these patients were transported by government ambulance. This is contrary to a study on prehospital transport practices by Sankar et $\mathrm{al}^{9}$ which showed poor utilization of ambulance services for transport of patients.

We found that the severity of illness was explained to the attendants in only a minority of cases (16.5\%). In addition, most of the children were transported without any accompanying health personnel (doctor/nursing staff) (92.75\%). The study by Sankar et $\mathrm{al}^{9}$ also showed that there was neither prior communication with the staff of the higher facility nor there was accompanying health personnel during referral to their facility. In children with severe illness, referral without adequate stabilization or monitoring during transport can lead to further deterioration of the health of sick child.

In our study, the most common cause for referral was nonavailability of beds in the referring facility $(42.25 \%)$. Other causes for referral were need for NICU care (20.5\%), PICU care (14.5\%), or further management of a disease (12.25\%). Daudi et $\mathrm{al}^{10}$ studied the referral pattern in an African national referral hospital. The main reasons for referring patients were lack of expertise (96.3\%) and lack of necessary equipment.

A study by Shahab et $\mathrm{al}^{8}$ also showed that the most common cause for admission of children in a tertiary care hospital was for respiratory disorders, just as in our study. Saleem et $\mathrm{al}^{11}$ studied the pattern of neonatal admissions in a tertiary care hospital and found birth asphyxia was the most common cause followed by prematurity and its complications and sepsis which was similar to our study.

Fifty-four percent of the study patients had an Irish PEWS score of 1 to 5 . Patients with this illness severity can be managed at referring hospitals if attempts are made at strengthening their basic services. Similar findings have been reported in Zimbabwe, where $60 \%$ of the patients admitted to the national hospital were inappropriate for that level. ${ }^{12}$

The majority (59.75\%) of patients were discharged alive (-Table 6). Death occurred in $19.25 \%$ of the study population. Children who died had a higher severity score at admission, with a mean score of 15.68 , indicating a greater severity of illness. The patients who had outcomes other than death had
Table 6 Outcome of referred patients

\begin{tabular}{|l|l|l|l|}
\hline S. no & Outcome & Frequency & Percentage \\
\hline 1. & Discharged & 239 & 59.75 \\
\hline 2. & Died & 77 & 19.25 \\
\hline 3. & $\begin{array}{l}\text { Left against medical } \\
\text { advice (LAMA) }\end{array}$ & 60 & 15 \\
\hline 4. & Absconded & 15 & 3.75 \\
\hline 5. & Referred & 9 & 2.25 \\
\hline & Total & 400 & 100 \\
\hline
\end{tabular}

lower scores $(<7)$. The maximum deaths occurred within first 24 hours ( $44.15 \%)$ of admission.

There was a significant correlation between age and outcome (mortality) and it was evident that the risk of death decreased as age increased. Infants had significantly higher scores compared with other age groups. No correlation was found between gender and outcome. Among the clinical disorders, neonatal illnesses and neurological disorders (e.g., meningitis) had a significantly higher risk of mortality than that of cardiovascular disorders.

Patients with higher PEWS score had a significantly increased risk of mortality. By an increase in the score of 1 unit, the risk of mortality significantly $(p<0.0001)$ increased by odds of 3.7531. This suggests that the PEWS score is a useful tool for triaging patients and in planning resource allocation to admitted patients.

The limitations of our study are a relatively small sample size (400), a problem with assessment of severity at presentation (patients partially stabilized in emergency department before being referred to the ward for assessment), and a scoring system based only on clinical signs. Though this increases its ease of use, utilization of scores with additional laboratory parameters can provide more detailed estimates of severity at admission.

The study has generalizability to other tertiary care hospitals in North India because of similar socioeconomic factors existing in the area and also because patients were referred to our hospital from several neighboring states. However, our data may not be generalizable to other geographical areas.

The profile of patients seen in our study suggests that strengthening neonatal services, by providing basic equipment like radiant warmers and phototherapy units and providing training to referring district hospitals can enable provision of care nearer the family's home. This can potentially be beneficial to families, causing less disruption of family life and less economic hardship.

In addition, our study revealed a greater need for stabilization and communication at the time of referral. Attention to these measures has previously been shown to improve the outcome of pediatric patients. ${ }^{13}$

In addition, routine utilization of the Irish PEWS scoring system at the emergency department can help in early identification of severe illness in the referred children and thus prioritize the therapeutic interventions. 
e198 Clinical Profile and Outcome of Children Referred to a Hospital in North India Eswaramoorthy et al.

\section{Ethical Approval}

Ethical approval was taken from institutional review board (reference number IEC/VMMC/SJH/Thesis/July/ 2016/1073, dated June 28, 2018).

\section{Authors' Contributions}

B.E., R.G., and M.B. were involved in patient care. All authors were involved in the preparation of manuscript and planning and execution of the study.

\section{Funding}

None.

\section{Conflict of Interest}

None declared.

\section{References}

1 Ma S, Sood NA. Comparison of the Health Systems in China and India. CA: Rand Corporation; 2008

2 MOHFW Indian Public Health Standards. Revised guidelines- New Delhi Directorate General of Health Services, Ministry of Health and Family Welfare, Govt. of India 2012. Accessed April 3, 2016 at: http://nrhm.gov.in/nhm/nrhm/guidelines/indian-public-healthstandards.html

3 Aggarwal KC, Gupta R, Sharma S, Sehgal R, Roy MP. Mortality in newborns referred to tertiary hospital: an introspection. J Family Med Prim Care 2015;4(03):435-438
4 Singhi S, Singhi S, Gupta G. Comparison of pediatric emergency patients in a tertiary care hospital vs a community hospital. Indian Pediatr 2004;41(01):67-72

5 Marcoux D, Nadeau K, McCuaig C, Powell J, Oligny LL. Pediatric anogenital warts: a 7-year review of children referred to a tertiary-care hospital in Montreal, Canada. Pediatr Dermatol 2006;23(03):199-207

6 Doyle DJ. Clinical early warning scores: new clinical tools in evolution. Open Anaesth J 2018;12:26-33

7 Paediatric Early Warning System (PEWS). Available at: https:// www.rcpi.ie/paediatric-early-warning-system/

8 Shahab N, Munir S, Bhatti N. Analysis of pediatric medical admission pattern to a tertiary care hospital. Ann Pak Inst Med Sci 2010;6(04):219-222

9 Sankar J, Singh A, Narsaria P, Dev N, Singh P, Dubey N. Prehospital transport practices prevalent among patients presenting to the pediatric emergency of a tertiary care hospital. Indian J Crit Care Med 2015;19(08):474-478

10 Simba DO, Mbembati NA, Museru LM, Lema LE. Referral pattern of patients received at the national referral hospital: challenges in low income countries. East Afr J Public Health 2008;5(01):6-9

11 Saleem M, Iqbal R, Bokhari S, Ali M, Khan Z. Pattern of neonatal admissions $\&$ its outcome in a tertiary care hospital of Southern Punjab (a 5 year study). Pakistan J Med Health Sci 2014;8(04):916

12 Sanders D, Kravitz J, Lewin S, McKee M.Zimbabwe's hospital referral system: does it work? Health Policy Plan 1998;13(04):359-370

13 Ezhumalai G, Jayashree M, Nallasamy K, Bansal A, Bharti B. Referrals to a pediatric emergency department of a tertiary care teaching hospital before and after introduction of a referral education module-a quality improvement study. BMC Health Serv Res 2020;20(01):761 